\title{
Sustaining remote-area programs: retinal camera use by Aboriginal health workers and nurses in a Kimberley partnership
}

\author{
Richard B Murray, Sue M Metcalf, Philomena M Lewis, Jacqueline K Mein and lan L McAllister
}

T ype 2 diabetes mellitus and its complications are hyperendemic among Aboriginal populations in Australia, affecting up to $25 \%$ of adults. ${ }^{1}$ In spite of this, access to primary health care is poor, and expenditures are grossly inequitable. ${ }^{2,3}$ Primary care providers serving Aboriginal populations are often overwhelmed by acute care needs. Implementing and sustaining culturally safe programs to screen for chronic disease and provide effective continuing care is therefore a significant challenge. We describe how a distributed model of diabetic retinopathy screening was conceived, implemented, refined and sustained in a remote region over 10 years and present an analysis of activity and outcomes, updating a preliminary report. ${ }^{4}$

\section{Setting of the program}

The Kimberley is a remote region of northwest Australia with a population of 42000 , $40 \%$ of whom are Aboriginal. The region includes six towns and over 100 Aboriginal communities across an area twice the size of the state of Victoria. Health services include public hospitals and associated community health services in towns, a network of five Aboriginal community controlled health services (ACCHSs) providing primary care, more than a dozen remote health posts supported by the ACCHSs or the Western Australian Government, and two private general practices in the town of Broome. The Kimberley Aboriginal Medical Services Council is a resource body jointly owned by member ACCHSs which provides regional services, including population health, workforce education and corporate services. The Kimberley Population Health Unit (KPHU) is a government agency with

\section{ABSTRACT}

Objective: To describe how a novel program of diabetic retinopathy screening was conceived, refined and sustained in a remote region over 10 years, and to evaluate its activities and outcomes.

Design: Program description; analysis of regional screening database; audit of electronic client registers of Aboriginal community controlled health services (ACCHSs).

Setting and participants: 1318 Aboriginal and 271 non-Aboriginal individuals who underwent retinal screening in the 5 years to September 2004 in the Kimberley region of north-west Australia; 11758 regular local Aboriginal clients of Kimberley ACCHSs as at January 2005.

Main outcome measures: Characteristics of clients and camera operators, prevalence of retinopathy, photograph quality, screening intervals and coverage.

Results: Among Aboriginal clients, $21 \%$ had diabetic retinopathy: $19 \%$ with nonproliferative retinopathy, $1.2 \%$ with proliferative retinopathy, and $2.8 \%$ with maculopathy. Corresponding figures for non-Aboriginal clients were $11 \%, 11 \%, 0$ and $0.4 \%$, respectively. Photograph quality was generally high, and better for non-Aboriginal clients, younger Aboriginal clients and from 2002 (when mydriatic use became universal). Quality was not related to operator qualifications, certification or experience. Of 718 regular Aboriginal clients with diabetes on local ACCHS databases, $48 \%$ had a record of retinal screening within the previous 18 months, and 65\% within the previous 30 months.

Conclusions: Screening for diabetic retinopathy performed locally by Aboriginal health workers and nurses with fundus cameras can be successfully sustained with regional support. Formal certification appears unnecessary. Data sharing across services, client recall and point-of-care prompts generated by electronic information systems, together with policies making primary care providers responsible for care coordination, support appropriate timely screening.

MJA 2005; 182: 520-523

regional responsibilities in disease surveillance, support of effective health care and management of community health and remote clinics. Aboriginal health workers are key members of the health workforce with roles including clinical care, education and liaison.

\section{Development of the program}

In 1995, the Kimberley Aboriginal Medical Services Council began a program of retinal screening in Kimberley ACCHSs using an

Kimberley Aboriginal Medical Services Council, Broome, WA.

Richard B Murray, MB BS, MPH\&TM, Medical Director; and Associate Professor, School of Public

Health and Tropical Medicine, James Cook University, Townsville, QLD; Sue M Metcalf, MPH\&TM,

Population Health Coordinator; Philomena M Lewis, AHW, Eye Program Coordinator.

Disease Control, Kimberley Population Health Unit, Broome, WA.

Jacqueline K Mein, MB BS, FACShM, MAE, Population Health Medical Officer.

Lions Eye Institute, Centre for Ophthalmology and Visual Science, University of Western

Australia, Nedlands, WA.

Ian L McAllister, FRANZCO, Associate Professor.

Reprints will not be available from the authors. Correspondence: Dr Richard B Murray, School of

Public Health and Tropical Medicine, James Cook University, Townsville, QLD 4810.

richardm@kamsc.org.au

auto-focus, 45-degree, "non-mydriatic" fundus camera (Canon CR4-UAF). The camera was operated initially by two local Aboriginal health workers and an Aboriginal nurse who had attended a short, structured training course in Perth, assisted by the Lions Eye Institute and the Royal Perth Hospital. These operators trained and supported others. An ophthalmologist from the Lions Eye Institute (I L M) agreed to report on the Polaroid photographs on an honorary basis, and referral forms and procedures were developed.

Before the program, visiting ophthalmologists from Perth (2000-3000 km distant) provided periodic retinal screening through clinics at most public hospitals. Receptiveness for a more accessible, less conventional approach was generated by the increasing number of presentations of end-stage diabetic retinopathy (especially maculopathy) and an estimated screening rate of less than $10 \%$.

Although screening using non-mydriatic fundus cameras was yet to be widely accepted 
1 Support for local retinal screening programs from regional staff

- Training and assisting local workers

- Feedback to camera operators on photograph quality and findings

- Assistance and training in use of patient information systems

- Ensuring all other routine aspects of diabetes care are undertaken

- Supporting function of local specialist referral and follow-up

- Monitoring program activity and reporting to local health staff and management

in 1995, and a role for Aboriginal health workers as operators was new, ${ }^{5}$ the program was quickly taken up by other WA providers ${ }^{6}$ and was introduced into government-run health services by KPHU in 1997.

In 2000, a publicly funded, fee-for-service arrangement was negotiated for ophthalmologists reporting on all screening photographs. In the same year, a regional retinal-screening database was established by the KPHU in partnership with the Kimberley Aboriginal Medical Services Council, to support central batch collation, reporting, payments and follow-up for screening photographs from all providers.

KPHU, assisted by the Lions Eye Institute, implemented a structured training and formal certification system for government health service staff. Since 2004, periodic training sessions have been run jointly with the Kimberley Aboriginal Medical Services Council. Camera use by government providers is coordinated by a nurse based in a regional hospital, and screening is organised using local retinal-screening registers and lists generated 6-monthly from the regional database.

In contrast, ACCHSs have relied on informal, practice-based training and have emphasised integration of retinal screening into the primary care management of diabetes. Scheduling is achieved using local computerised patient information and recall systems designed to prompt integrated care for clients across multiple health conditions (Ferret software, Pen Computer Systems, Sydney, NSW). The ACCHSs initially shared a single camera which they rotated quarterly. Breaks to routine and deskilling in the intervals proved a problem, and the strategy shifted to active recall and shorter rotation cycles. Sustaining a high level of program activity became easier once Polaroid film cameras were purchased for each ACCHS in 2002, and a regional Aboriginal health worker (PL) with support func- tions was appointed with national program funding (Box 1). ${ }^{7}$

Retinal screening in the Kimberley is now conducted by local workers using non-mydriatic fundus cameras. As well as being available in most towns, cameras are transported to large communities. The screening process includes measurement of visual acuity, pinhole refraction and photography of the fundus (and lens if the view of the fundus is substandard). Routine instillation of mydriatic drops (tropicamide $1 \%$ and phenylephrine $2.5 \%$ ) became universal from late 2002. The reporting ophthalmologist recommends attendance at a clinic as warranted by the degree of retinopathy or cataract. The program has significantly freed specialist consulting and procedural time.

\section{METHODS}

We investigated the activity and outcomes of the Kimberley retinal-screening program over its second 5 years of operation to assess and improve quality of care. Data were obtained from two sources: the regional retinal-screening database and local ACCHS client registers.

As the study was a quality assurance and clinical audit, formal ethics approval was not obtained. However, in keeping with ethical obligations, we obtained prior endorsement from the regional representative Aboriginal council of ACCHS boards for analysis, publication and dissemination of the findings.

\section{Data sources}

\section{Regional screening database}

Data sheets on all screening photographs have been completed by the reporting ophthalmologist and entered into a regional database held at KPHU since 2000 (this included batches of photographs taken in late 1999).

The reporting ophthalmologist grades diabetic retinopathy according to the modified Airlie House classification. ${ }^{8}$ Photograph qual-

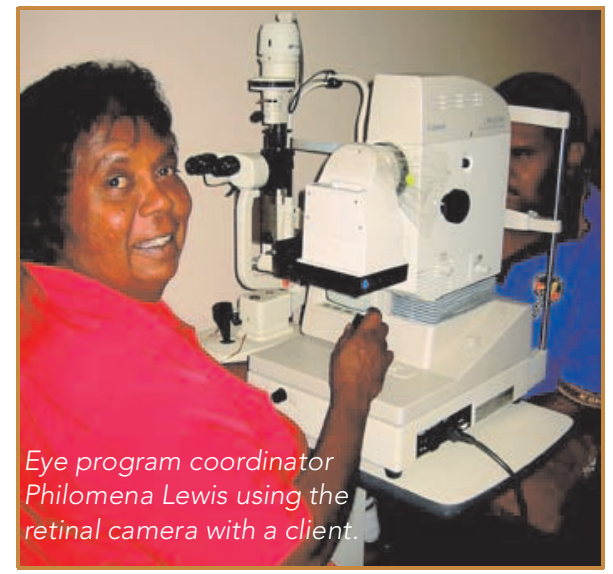

ity is also rated as excellent (well centred on macula, no artefact and sufficient clarity to reveal four or more vascular subdivisions and microaneurysms), adequate (generally well centred and sufficient clarity to reveal three vascular subdivisions and vision-threatening retinopathy, but not microaneurysms; possibly some artefact) or inadequate (reveals two or less subdivisions and either decentred or partially obscured by artefact; microaneurysms, small blot haemorrhages and small hard exudates generally not discernible). ${ }^{6}$

We classified episodes of screening as adequate or better if individual photographs were rated adequate and/or excellent for both eyes (or for one eye if it was the only one examined). Patients were classified with non-proliferative diabetic retinopathy if this condition was found in one or both eyes on any occasion, unless proliferative diabetic retinopathy was found on any occasion (in which case the patient was classified with the latter). Sightthreatening retinopathy was defined as the presence of maculopathy and/or proliferative diabetic retinopathy. Diabetic retinopathy included non-proliferative and proliferative diabetic retinopathy and any lesion reported as "quiescent" diabetic retinopathy.

\section{Primary-care client databases}

Local patient information and recall data from the electronic client registers of the Kimberley ACCHSs were audited in January 2005 to determine characteristics of "regular" Aboriginal clients of the ACCHS retinal-screening program. Data were obtained from the registers of four ACCHSs; clients of the fifth ACCHS (the remote Jurrugk Health Service) were included in the Derby register.

Regular clients were defined as residents in the local area for whom the health service assumes responsibility for care coordination. The proportion of regular clients with diabetes who had undergone retinal screening was determined across six clinic sites (data for the two largest outlying clinics in the Broome ACCHS area were classified separately). The home address of clients was classified as "town" or "remote" across all clinic sites.

\section{Statistical analysis}

Data were analysed using SPSS version 6.1.3 (SPSS, Chicago, Ill). ${ }^{9}$ For univariate analysis, results are presented as proportions of available data and their confidence intervals, calculated using a normal approximation. Bivariate relationships were examined using $\chi^{2}$ tests. Explanatory variables were considered for entry into a logistic regression model of screening quality 


\begin{tabular}{|c|c|c|}
\hline & Aboriginal & Non-Aboriginal \\
\hline Total no. of clients & 1318 & 271 \\
\hline No. of women & $816(62 \%)$ & $88(32 \%)$ \\
\hline Mean client age at last screen in years $(95 \% \mathrm{Cl})$ & $50.6(50.8-51.3)$ & $54.6(53.1-56.1)$ \\
\hline No. of clients aged $\geqslant 55$ years at last screen & $486 / 1302(37 \%)$ & $141 / 266(53 \%)$ \\
\hline No. of episodes of screening & $2147(83 \%)$ & $440(17 \%)$ \\
\hline \multicolumn{3}{|l|}{ Proportion of episodes where operator } \\
\hline Was Aboriginal health worker & $855 / 2120(40 \%)$ & $50 / 433(12 \%)$ \\
\hline Had performed $<20$ screens & $408 / 2120(19 \%)$ & $64 / 433(15 \%)$ \\
\hline Had formal training and certification & $701 / 2119(33 \%)$ & $276 / 433(64 \%)$ \\
\hline \multicolumn{3}{|l|}{ Proportion of episodes rated adequate or excellent } \\
\hline Overall & 1802/1975 (91\%) & $418 / 421$ (99\%) \\
\hline After 2002 & $759 / 804(94 \%)$ & 183/184 (99\%) \\
\hline For patients aged $<55$ years & 1126/1164 (97\%) & 196/197 (99\%) \\
\hline For patients aged $\geqslant 55$ years & $659 / 792(83 \%)$ & $218 / 220(99 \%)$ \\
\hline For patients aged $\geqslant 65$ years & $266 / 364(75 \%)$ & $77 / 79(98 \%)$ \\
\hline Where operator has formal certification & $619 / 679(91 \%)$ & $271 / 273(99 \%)$ \\
\hline Where operator is Aboriginal health worker & 698/767 (91\%) & $44 / 44(100 \%)$ \\
\hline Where operator had performed $<20$ screens & $351 / 385(91 \%)$ & $64 / 64(100 \%)$ \\
\hline No. of second or subsequent screening episodes & $864 / 2147(40 \%)$ & $170 / 440(39 \%)$ \\
\hline Screening interval 9-29 months & $618 / 864(72 \%)$ & $143 / 170(84 \%)$ \\
\hline Screening interval $<9$ months & $140 / 864(16 \%)$ & $15 / 170(8.8 \%)$ \\
\hline No. of clients with assessable photographs & 1240 & 259 \\
\hline \multicolumn{3}{|l|}{ Outcomes (\% of assessable clients; $95 \% \mathrm{Cl}$ ) } \\
\hline Diabetic retinopathy (DR) & $254(21 \% ; 18 \%-23 \%)$ & $28(11 \% ; 7 \%-15 \%)$ \\
\hline Non-proliferative DR ( \pm maculopathy) & 239 (19\%; 17\%-21\%) & 28 (11\%; 7\%-15\%) \\
\hline Proliferative DR & $15(1.2 \% ; 0.6 \%-1.8 \%)$ & 0 \\
\hline Maculopathy & $35(2.8 \% ; 1.9 \%-3.7 \%)$ & $1(0.4 \%)$ \\
\hline Sight-threatening DR & $44(3.5 \% ; 2.5 \%-4.6 \%)$ & $1(0.4 \%)$ \\
\hline Mean age of those with DR in years $(95 \% \mathrm{Cl})$ & $53.3(51.8-54.7)$ & $57.1(55.5-58.7)$ \\
\hline
\end{tabular}

based on bivariate relationships and clinical interest.

\section{RESULTS}

\section{Regional screening database}

A total of 2587 episodes of retinal screening were recorded on the KPHU regional database between October 1999 and September 2004. These involved 1589 clients and 37 camera operators (11 Aboriginal health workers, 20 registered nurses, three medical practitioners and three others).

Characteristics of clients and screening episodes are shown in Box 2. Data on photograph quality were available for $91 \%$ of episodes (excluding a single batch of 39 unreadable photographs in 2000 caused by camera malfunction). The proportion of episodes rated adequate or better was $91 \%$ for Aboriginal clients and 99\% for non-Aboriginal clients.
Assessment of retinal pathology for one or both eyes was available for $94 \%$ of clients. An estimated $98 \%$ of Aboriginal clients had type 2 diabetes. Diabetic retinopathy was found in $21 \%$ of Aboriginal clients, and sight-threatening retinopathy in $3.5 \%$. Corresponding figures for non-Aboriginal clients were $11 \%$ and $0.4 \%$, respectively.

The target screening interval was $1-2$ years. The proportion of clients rescreened in less than 9 months is a measure of overscreening. This was higher in the period up to 2002: 22\% of screening intervals were less than 9 months for clients who had a subsequent screen (69/313). This dropped to $13 \%$ (71/551) from 2003, when doublescreening by different health care providers was recognised as a problem (resolved by local coordination of screening and regional agreement that the "usual primary care provider" bore responsibility for scheduling/ recall).
Logistic regression analysis of explanatory variables for screening quality is shown in Box 3. The proportion of episodes rated adequate or excellent was higher among nonAboriginal clients and after 2002, when mydriatic use became universal. Among Aboriginal clients, the quality of photographs declined sharply after age 55 years. Screening quality was not related to client sex, whether the camera operator was an Aboriginal health worker, nor the operator's formal certification status or experience. Around 98\% of episodes of screening for Aboriginal people aged under 55 years can be expected to be of adequate or excellent quality, and 91\% for those aged 55 years or over (Box 3).

\section{Primary-care client databases}

The characteristics of regular local Aboriginal clients of ACCHSs at January 2005 are summarised in Box 4. There were 718 clients aged 20 years and over with diabetes. The proportion of these coded as having had at least one retinal examination in the preceding 18 months varied from $30 \%$ to $71 \%$ across the six clinic sites, and in the preceding 30 months from $59 \%$ to $76 \%$. Town residents were more likely to have been screened than those in remote communities (odds ratio, $1.8-2.0 ; P<0.01)$.

\section{DISCUSSION}

We found that the prevalence of diabetic retinopathy among Aboriginal clients of the Kimberley retinal-screening program was $21 \%$. The mean age of those with diabetic retinopathy was 53.3 years. Quality of retinal photographs was generally high, and better for non-Aboriginal clients, younger Aboriginal clients and from 2002 (when mydriatic use became universal). Quality was not related to operator qualifications, certification or experience. Of the regular Aboriginal clients with diabetes on local ACCHS databases, $48 \%$ had a record of retinal screening within the previous 18 months, and $65 \%$ within the previous 30 months.

The prevalence of retinal pathology in the Aboriginal population with diabetes in the Kimberley region is similar to the prevalence reported for Aboriginal populations in the Northern Territory. ${ }^{10}$ Prevalence of diabetic retinopathy in Australian surveys varies depending on whether only those with selfreported diabetes are examined $\left(22 \%{ }^{11}\right.$ to $29 \%{ }^{12}$ ) or whether people newly found to have diabetes on screening are included $\left(15.3 \%^{11}\right)$. As care protocols for Aboriginal adults in the Kimberley include annual 


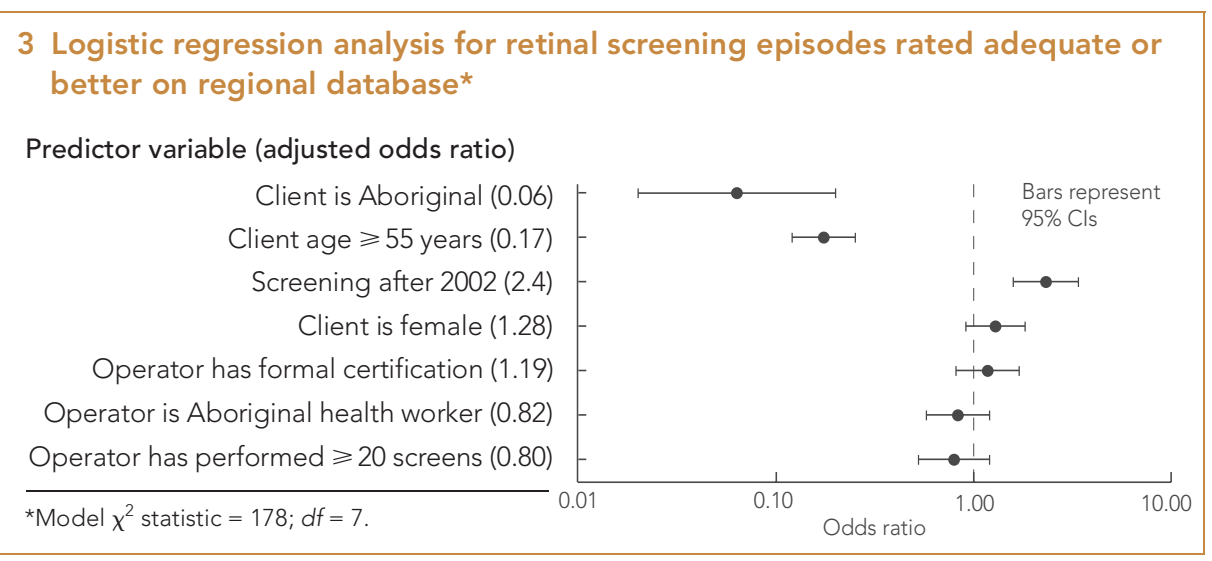

4 Data on regular Aboriginal clients of Kimberley Aboriginal community controlled health services (ACCHSs), January 2005

\begin{tabular}{lccc} 
& Male & Female & Total \\
\hline Total no. of clients & 5765 & 5993 & 11758 \\
No. aged $\geqslant 20$ years & $3154(55 \%)$ & $3338(56 \%)$ & $6492(55 \%)$ \\
No. of those aged $\geqslant 20$ years coded with diabetes & $275(8.7 \%)$ & $443(13 \%)$ & $718(11 \%)$ \\
Mean age of clients with diabetes (95\% Cl) & 51.7 & 50.8 & 51.1 \\
& $(50.2-53.3)$ & $(49.5-52.0)$ & $(50.1-52.1)$ \\
No. with diabetes screened in previous 18 months & $115(42 \%)$ & $226(50 \%)$ & $341(48 \%)$ \\
No. of these from towns & $87(46 \%)$ & $174(56 \%)$ & $261(52 \%)$ \\
No. of these from remote communities & $28(32 \%)$ & $52(40 \%)$ & $80(37 \%)$ \\
No. with diabetes screened in previous 30 months & $165(60 \%)$ & $303(68 \%)$ & $468(65 \%)$ \\
No. of these from towns & $124(65 \%)$ & $227(73 \%)$ & $351(70 \%)$ \\
No. of these from remote communities & $41(47 \%)$ & $76(58 \%)$ & $117(54 \%)$
\end{tabular}

screening for diabetes, the crude prevalence of diabetic retinopathy among those with diabetes $(21 \%)$ may be higher than that of the general Australian diabetic population. Kimberley Aboriginal people with diabetic retinopathy are over a decade younger on average (53.3 years compared with 65 years). ${ }^{11}$

We found that operation of a fundus camera is readily learned in primary care, and that the volume of experience needed to achieve proficiency appears to be low. Similarly, another study found no difference in retinal image quality between a professional ophthalmic photographer and an operator with an hour of instruction in the use of a fundus camera and experience with 10 clients. ${ }^{13}$ Indistinct images are readily recognised, and the procedure can be repeated immediately. Consequently, formal certification appears unnecessary for operators of non-mydriatic fundus cameras.

The level of retinal screening coverage among regular Aboriginal clients with diabetes on ACCHS databases is probably an underestimate because of incomplete local data-capture. However, even this underestimate compares well with reports from other populations. ${ }^{14-17}$
This study shows that a devolved program of screening for retinal complications of diabetes in a remote Aboriginal population can be successfully performed by Aboriginal health workers and nurses using non-mydriatic fundus cameras and sustained over time with regional program support. Data sharing across services, client recall lists and point-ofcare prompts generated by patient information systems, together with policies that make primary health care providers responsible for care coordination, help support timely screening while avoiding over-screening. These findings are consistent with a recent review of the National Aboriginal and Torres Strait Islander Eye Health Program. ${ }^{7}$

\section{ACKNOWLEDGEMENTS}

We acknowledge Dr Peter Graham for his vision and early championship of the program, the late Matthew Wade and Chris Barry for training efforts, the many dedicated camera operators, and local Aboriginal boards of Kimberley ACCHSs for their interest and support.

\section{COMPETING INTERESTS}

None identified.

\section{REFERENCES}

1 De Courten M, Hodge A, Dowse G, et al. Review of the epidemiology, aetiology, pathogenesis and preventability of diabetes in Aboriginal and Torres Strait Islander populations. Canberra: AGPS, 1998.

2 Dwyer J, Silburn K, Willson G. National Strategies for Improving Indigenous Health and Health Care. Canberra: Australian Government Department of Health and Ageing, 2004. Available at: http:// www.health.gov.au/oatsih/phc (accessed Mar 2005).

3 Australian Institute of Health and Welfare. Expenditures on health services for Aboriginal and Torres Strait Islander people 1998-99. Canberra: AlHW and Commonwealth Department of Health and Aged Care, 2001. (AlHW Catalogue No. AlHW 7). Available at: http://www.aihw.gov.au/publications/ ihw/ehsatsip98-99/ (accessed Feb 2005).

4 Mak DB, Plant AJ, McAllister I. Screening for diabetic retinopathy in remote Australia: a program description and evaluation of a devolved model. Aust J Rural Health 2003; 11: 224-230.

5 Karagiannis A, Newland HS. Mobile retinal photography: a means of screening for diabetic retinopathy in Aboriginal communities. Aust $N Z J$ Ophthalmol 1996; 24: 333-337.

6 Diamond JP, McKinnon M, Barry C, et al. Nonmydriatic fundus photography: a viable alternative to fundoscopy for identification of diabetic retinopathy in an Aboriginal population in rural Western Australia? Aust NZJ Ophthalmol 1998; 26: 109-115.

7 National Aboriginal and Torres Strait Islander Eye Health Program. Canberra: Australian Government Department of Health and Ageing. Available at: http://www.health.gov.au/internet/wcms/publishing.nsf/Content/health-oatsih-eyehealth-index.htm (accessed Feb 2005).

8 Early Treatment Diabetic Retinopathy Study Research Group. Fundus photographic risk factors for progression of diabetic retinopathy. ETDRS report number 12. Ophthalmology 1991; 98 (5 Suppl): 823-833.

9 SPSS Inc. SPSS version 6.1.3 Chicago III: SPSS Inc.

10 Jaross N, Ryan P, Newland H. Prevalence of diabetic retinopathy in an Aboriginal Australian population: results from the Katherine Region Diabetic Retinopathy Study (KRDRS). Report no. 1. Clin Experiment Ophthalmol 2003; 31: 6-7.

11 Tapp RJ, Shaw JE, Harper CA. The prevalence of and factors associated with diabetic retinopathy in the Australian population. Diabetes Care 2003; 26: 1731-1737.

12 McKay R, McCarty CA, Taylor HR. Diabetic retinopathy in Victoria, Australia: the Visual Impairment Project. Br J Ophthalmol 2000; 84: 865-870.

13 Maberley D, Morris A, Hay D, et al. A comparison of digital retinal image quality among photographers with different levels of training using a non-mydriatic fundus camera. Ophthalmic Epidemiol 2004; 11: 191-197.

14 Kaur H, Maberley D, Chang A, Hay D. The current status of diabetes care, diabetic retinopathy screening and eye-care in British Columbia's First National Communities. Int J Circumpolar Health 2004; 63: 277-285

15 Tapp JR, Zimmet PZ, Harper CA, et al. Diabetes care in an Australian population: frequency of screening examinations for eye and foot complications of diabetes. Diabetes Care 2004; 27: 688-693.

16 Brechner RJ, Cowie CC, Howie LJ, et al. Ophthalmic examination among adults with diagnosed diabetes mellitus. JAMA 1994; 27: 1714-1718.

17 Wilson A, Baker R, Thomson J, Grimshaw G. Coverage in screening for diabetic retinopathy according to screening provision: results from a national survey in England and Wales. Diabetes Med 2004; 21 : 271-278.

(Received 21 Feb 2005, accepted 12 Apr 2005) 